\title{
Faculty of Social Sciences, University of Tirana: "Assessment of the Standards of Social Care for Victims of Trafficking in Albania"
}

\section{Suela Hana}

\author{
Doi:10.5901/ajis.2015.v4n3s1p152
}

\begin{abstract}
Approaches to public policy evaluation in the study consist of one or more criteria: -Justice, which verifies that the objectives of an intervention sufficiently cover all dimensions of socio-economic problem that it regulates. -Efficiency, which verify that the expected effects of an intervention are achieved thanks to the actions performed.-Usefulness, which verifies the justification of a challenge against not only the expected, but also against other side effects produced, especially the possible negative effects.-Internal coherence, which verifies that different strategic objectives and operational program are in a logical relation between them, that they are complementary and not inflated.-External coherence, which verify that the objectives of an intervention or contribute correspond to those of other policies of the institution or other institutions operating on the territory and there are, on the contrary, contradictory or antagonistic. -Stability, which verify that the results achieved are not fragile or achievements that "break" quickly but have consistency in time to be considered as real achievements. -Qualifying, It examines whether the action taken has increased the capacity and competence of operators who have participated. This paper aims to assess and identify the most critical issues dealing with social care standards for victims of in Albania, specifically in the National Reception Center for Victims of Trafficking, focusing on the study criteria efficiency and sustainability.
\end{abstract}

Keywords: victims of trafficking, standards, justice, efficiency, usefulness, internal coherence.

\section{Introduction}

Albania, which is a country in transition for more than two decades, has experienced major economic, political and social changes. The efforts of the Albanian society to ensure economic growth and social development are associated with previously unknown several challenges, including poverty, extreme unemployment, lack of job opportunities and lack of basic social services, involving here education and health, and a massive wave of emigration. The Albanian government developed its social policy, as part of the political changes in the 90s, treating issues of victims 'trafficking in full compliance with the principles of the Convention of the Human Rights, ratified by the Government in $1996^{1}$, which made the necessary improvements in the legislation, in order to provide a protective environment for the victims of trafficking .

Finally, the 2011-20132 National Action Plan on combating trafficking of human beings, identifies a set of strategical and generally institutional priorities, to monitor the implementation of the rights of trafficking victims in their residential centres.

\section{Assessment Approaches to Public Policy}

Approaches to public policy evaluation are related to the study of one or more criteria3:

- Justice, which verifies that the objectives of an intervention can sufficiently cover the dimensions of the socialeconomic problem that it regulates.

- Effectiveness, which verifies that the expected outcome of an intervention is achieved thanks to the actions carried out.

- Efficacy which verifies that the results have been achieved at a reasonable cost, compared to other types of intervention.

- Usefulness which verifies the justification of the intervention not only related to the expected effects, but also to other side effects arising, especially the eventual negative effects.

\footnotetext{
${ }^{1}$ Ratified by Law no. 8137, date12.08.1996, the Official Journal of 20 August 1996

${ }^{2}$ Republic of Albania, the National Action Plan 2011-2013.

${ }^{3}$ Allan Mac Connell,Understanding Policy Success, 2010 p.101.
} 
- Internal coherence which verifies that various strategic and operating objectives of a program have a logical relation, so that they can be complementary but not inflated.

- External coherence which verifies that the objectives of an intervention correspond or contribute to those other policies of the institution or other institutions, which operate on the territory and are not, on the contrary, contradictory or antagonistic.

- Stability which verifies that the results achieved are not fragile or "break" quickly but have consistency in time so that they can be considered real achievements.

- Capability, decides whether the action taken has increased the capacity and competence of the operators who have participated.

\section{The Aim and Types of Services}

The service provider offers a complete and efficient package of services, in accordance with the complex needs of the beneficiaries, in cooperation with the primary and alternate provider, to ensure the protection of people at risk of trafficking as well as the rehabilitation and reintegration of those who are already victims of trafficking.

The National Reception Centre for Victims of Trafficking in Tirana has published leaflets and informative materials in two languages (Albanian and English), special ones for children and women being trafficked, leaflets which involve (i) the purpose and mission of the Centre establishment and functioning (ii) targeted vulnerable groups and services offered in this institution (iii) the organizational methods of services, (iv) collaborators etc.

In these information materials the centre has reflected only the first set of services described in the standard 1 , starting from the specific profile of this center (center of high security) and based on article 589, date 28. 08. 2003 "On the establishment and operation of the National Host Center for the Victims of Trafficking", Article No. 7710, date 18.05.1993 "On the Assistance and Social Care", by-laws for its implementation ${ }^{4}$, in accordance with the Convention of the Human Rights, as well as the mission defined for the establishment of this institution.

Referring to the Justice ${ }^{5}$ criterion, also regarding this standad, confusion is often created about the real services that this institution need to develop, as a result of uncertainty and lack of information given in the appendices in order to meet the standards as well as documents that do not respectively define specific services that residential and community institutions must offer.

\section{The Assessment of the Needs and the Care Plan for the Beneficiary}

Before I evaluate the elements of this standard, what is worrying in this large group of standards relates to the fact that, while talking about documentation, needs assessment, assistance programs, support staff,

etc., in the document of the Standards for Victims of Trafficking in Residential Centres, not a phrase or paragraph referring to the procedures to be followed for admission or age acceptance of the victims of trafficking in residential centres, has been written.

Trafficking victims are admitted to residential institutions based on referrals or contacts that the centres have with the State Police (Border Police, Office of the National Anti-traffic Coordinator) Regional Offices of SS in different parts, and other relevant organizations of this field, family etc. After the initial identification and interview of a referred case by the above-mentioned actors as a victim of trafficking or potential risk of trafficking, the person accommodates in the respective institutions, always with his full willingness to receive the necessary services.

The organizational structure as well as a job description for each employee is an integral part of the internal regulation of the institution, a structure which is adapted to meet this standard. There have been constant changes within short periods of time regarding the professional staff in this institution, dismissing or hiring workers (who in many cases do not have relevant education, or they lack experience etc.). As a result the quality of services offered at this center has been improved. ${ }^{6}$

The "internal coherence" implementation, which verifies that the various strategic and operating objectives of a program have a logical relation, if they are complementary and not inflated, as well as the structure of constantly making

${ }^{4}$ MOLSAEO, Summary of Legislation and Policies in the Field of Social Protection in Albania, 2007.

${ }^{5}$ Allan Mac Connell, Understanding Policy Success, 2010 p.104.

${ }^{6}$ See Child Trafficking - the People Involved, 2012, p. 25. 
redundant and changes of the supportive staff constantly, indicates the low effectiveness of this standard, which is expressed by lowering to $\%$ of cases for victims of trafficking who undertake all the phases of the aid program. ${ }^{7}$

The profile of victims: age 14-20 years, they live in the village and are subjected to the restriction of liberty, rape, physical and psychological violence and sometimes even murder. As for their level of education, most of them have finished the 9-year school system. Most girls and women who are trafficked come from the lowest economic and social class or social groups that live in misery. ${ }^{8}$

Their physical profile is a proof of the negligence by their pimps, violence exercised by their users and lack of medical assistance given at the right time. They can have broken bones, gunshot or knife wounds, or cigarette burns and they often suffer from chronic respiratory and sexually transmitted infections, unwanted pregnancies and abortions performed in inadequate conditions. ${ }^{9}$

This profile of VT is a significant indicator, which shows not only the terrible conditions which they face during the exploitation for profit, but it also represents a useful and helpful element for the experts during the evaluation process of their needs for assistance. It is impossible to respect the time limit specified in this standard (2 weeks) taking into consideration the way in which they are treated during the trafficking time. Even when the evaluation is carried out within 2 weeks after VT's accommodation in the institution, experience has shown that the assessment was not accurate or complete, in accordance with the real needs of the victim.

This shows that the "Functionality," the excuse for an intervention in the expected effects, but also in the other side effects arisen, especially the eventual negative effects, is not true, and therefore the standard is problematic and not drafted in accordance with the problems on the first scene. Details of the Annual Report of the NRCVT ${ }^{10}$ show that during 2013, from 47 cases assisted, only 10\% of these cases, referring to the evaluation of psycho-social, educational and health needs were carried out by specialists within the time limit prescribed.

\section{The Rights and Responsibilities of the Beneficiaries}

From the monitoring of this standard, its main indicator, that is the display of the rights and obligations of beneficiaries in the apparent premices of the Center, is assessed and identified, in accordance with the language and specificity of the vulnerable group, where each beneficiary has equal opportunity to be informed and to profit quality services, thus avoiding gender, religious, or racial discrimination.

How real and genuine can this process be, when we talk about this particular group (children), not forgetting the fact that the majority of trafficked children, who come from the Roma community, are illiterate and do not have the right knowledge to write and understand the Albanian written language?!11

This is another unsolved problem, which experts of this field face, because they themselves do not possess the basic knowledge of the Roma language, but also knowledge of the outlook and culture of this community in our country. ${ }^{12}$

\section{Internal Management of the Service Center}

Personnel structure: The number of staff employed depends on the size and type of institution. There are three major groups: administrative staff, professional and support staff. In smaller institutions, the organizational structure is more simple, the ratio of beneficiaries with less personnel and where staff members perform a number of duties at the same time.

In Public residential institutions, administrative structure is as follows: ${ }^{13}$

Administrative personnel includes: the director, head of social service and the administrative head.

The Professional staff includes: a teacher, doctor, lawyer, psychologist, social workers.

\footnotetext{
${ }^{7}$ Annual Analysis of the State Social Service, 2013, p. 58.

${ }^{8}$ Baseline Survey Research, Section of the Central Region, IOM, September 2010.

9 It's here.

${ }^{10}$ Annual Report 2013 of the National Reception Center for Victims of Trafficking, p. 22.

11 It's here

12 Inspection Report of the Social Services Centres, SSS, October 2012.

${ }^{13}$ Instructions Mannual of the Minister of Labour, Social Affairs and Equal Chances no. 316, no. 10.02.2010 "Implementing Standards of

Social Care for Trafficked People or at risk of being trafficked."
} 
The Supportive staff includes: cleaners, cooks, maintenance workers and a driver.

Referring to the critera of "External coherence" for the assessment of policies, from research made, it is a known fact that there is no legal basis, procedures or terms of reference regarding the recruitment of staff, especially the staff of specialists in residential institutions (whether public or those run by non-profit organizations). Employment is not based on competition and not any particular attention is paid to the tendency of employees in respecting the rights of VT.

This results in the low performance of specialists, not well-qualified services, discontinuation of the aid program by $\mathrm{VT}$, therefore affecting the long-term sustainability of the functioning of the institution.

\section{Founding and the Cost for the Victims of Trafficking in the Center}

The "Ability" criterion, examines whether the action taken has increased the capacity and competence of the operators who have participated.

Regarding the temporary financing of the non-governmental organizations, it is insufficient, considering the needs and requirements which organizations in the aid of the traficking victims are having. ${ }^{14}$ This centers, except food, offer other services such as medical, psychological, legal, educational assistance, etc. It is known today that they have a high financial cost. The law has not well-defined the criteria, on the basis of which organizations should receive funds and how to ensure the sustainability of organizations when the funds provided by central and local government finish. This can lead to the abuse of funds or in the worst case the services will not be received by target groups.

\section{Conclusions}

- Monitoring capacities for the welfare of victims of trafficking after rehabilitation and reintegration are limited. This affects the process of "recycling" in the phenomenon of trafficking.

- Providing supportive social services through public and private residential institutions, represents the most widespread form of protection given to victims of trafficking in Albania. Meanwhile the world today recognizes and promotes many other forms of support such as volunteering communities, etc, casa family etc.

- Institutions spend $50-70 \%$ of their budget on administrative expenses (food, clothing, water, electricity, etc.) and about $10 \%$ is spent on social awareness and integration activities for victims of trafficking, community, society and families.

- Standards of working with victims of trafficking have not set clear policies in order to enable the reintegration of victims of trafficking in the family of origin. From 45 cases assisted in CCVT in 2013, only 5 of them were returned to their families, while the rest continued the assistance program at the reintegration center in Tirana, Elbasan and Vlora.

\section{Recommendations}

Referring to the criteria for the evaluation of the effectiveness and quality of the policies drafted to help vulnerable groups, theoretical basis, which intersects and converge towards expertise, should be given priority. After evaluating the standards starting by the theory it was shown that many policies appear problematic, unrealistic and not in accordance with the current needs and specifications of the country being referred for the phenomenon of trafficking.

It is the right time to improve the legal basis and the assistance policies for the victims of trafficking by:

- setting and respecting standards (environmental standards, quality of life standards, standards of outcomes, professionalism and commitment).

- supervising the services quality (licensing, accreditation and certification, periodic inspection and measurement of indicators, Ombudsman).

- By improving working conditions and processes (improving motivation, providing trainings, developing professional ethic, setting up the system and form of management, and ensurig the involvement of service providers). 


\section{References}

Annual Analysis 2013, the State Social Service, p. 58.

Allan Mac Connell, Policy Understanding Success, 2010, p. 101-105.

CAAHT, Annual Report, 2009, p.101.

Child Trafficking - the People Involved, 2012, p. 25.

European Convention for the Protection of Fundamental Human Rights, Official Journal 20 August 1996.

IOM, Baseline Survey Research, Section of the Region, September 2010.

Inspection of Social Service Centres, SSS, in October 2012.

Instructions Mannual of the Minister of Labour, Social Affairs and Equal Chances no. 316, dt 10.02.2010 "On the Application of Standards of Social Care Services for people being trafficked or at risk of being trafficked".

MOLSAEO, Summary of Legislation and Policy in the Field of Social Protection in Albania, 2007.

The National Reception Centre for Victims of Trafficking, Annual Report 2013, p 22.

The Republic of Albania, the National Action Plan 2011-2013 in the fight against trafficking of human beings. 


\title{
Issues of Order in Grammar and Studies of the Albanian Language
}

\author{
Doc. Dr. Aida Kurani \\ Aleksandër Moisiu" University Durrës, Albania
}

\section{Doi:10.5901/ajis.2015.v4n3s1p157}

\begin{abstract}
Our research aims to follow the path of order development of clauses, words and sentences through the periods of time in grammar and studies of the Albanian language. Highlighting the achievements regarding our issue and identifying the problems, we aim to pave the way for new studies on the order of Albanian language. Knowing that such achievements are necessary not only because there is an Albanian linguistic tradition in the study of the order, but also to shed light on the opinions related to the order in Albanian, as well as some problems concerning it. To see how such units are dealt with in our linguistics, we considered the known grammars of the Albanian language in a chronological order, starting from the earliest days until today. The focus of consultation for a series of issues closely related to our work has been also the research made by various local or foreign authors.
\end{abstract}

Keywords: order of clauses, order of sentences, period, syntax.

\section{Introduction}

The order of words and parts is one of the most important tools in forming a speech. It is conditioned by different factors and carries out several functions within a sentence. In the Albanian language, the order of words is relatively free, the parts of the speech can be put in different places without changing their syntax function. The order of periodic sentences is important for the structure and the value of the period. Ranking periods have a fixed and unchanged order due to semantic reasons. Any changes in them would lead to a change in the previous semantic relations. For instance, in the following speech "Kishte nxehtë dhe i pihej ujë", we cannot reverse its order, because we would ruin the meaning. In any other case, this order cannot change for structural reasons, i.e, in the second sentence, there are words that mention or refer to a word which is in the first sentence and a reversed order would be meaningless, for instance: "Urbani u ndal në qendër të qytetit dhe prej tij zbritën pasagjerët". Here, the phrase "prej tij" describes the word "urban", therefore we cannot have any other order. The change of order, in this case, would change the logical flow of events.

The order of ranking sentences cannot be changed, even when we have a passage of time, for instance: "Ajo hodhi dru në sobë dhe u ul pranë meje."

In the Albanian grammar, the order of composite periodical sentences with sub ranking words and the order of parts in these sentences has been dealt with very little. Spiro Flogi says that at least, up until the time that he wrote, the issue of the order of words in a sentence and the periodical sentences with sub ranked periodical sentences, has not been dealt with at all by Albanian syntaxologists or it has been dealt with to a very small extent. Floqi (1969: 125)

In his syntax, A. Xhuvani (1922:22), divides speeches into speeches with a direct order and speeches with an indirect order. Thus, the author divides sentences with an ordinary order: subject+predicate + direct object+adjunct and sentences with an unnatural order and vice versa.

Ilia Dilo Sheperi (1927) makes a more in depth analysis of the topic of order. Like A. Xhuvani, he divides sentences with an ordinary order and those with a non ordinary order and makes important remarks on the order of sub ranking sentences.

In his school text, Justin Rrota (1942), like prof. A Xhuvani, talks about the order in a simple speech and divides the direct order from the indirect order, which according to him, are defined by the position of the main parts subjectpredicate. In other words, we have a direct order, when the subject is in front of the direct object and when the direct object comes after the subject, then this is an indirect order of words in a speech.

The author also talks about the order of the second parts of the speech, also mentioning the order of short forms of the object or personal pronouns, which, like he points out, are located after the verb, if they are in the first person singular or plural, but they can even go before the verb without ruining the semantic of the sentence.

As far as the order of sub ranking sentences are concerned, J. Rrota says that in the Albanian language, the 